\title{
RECENS IONES
}

JUAN LUIS RUIZ DE LA PEÑA, La pascua de la creación. Escatología, BAC, Madrid ${ }^{3}, 2000$, 298 pp.

En el mes de junio de 2000 se ha publicado la tercera edición del Manual de Escatología escrito por el teólogo de Oviedo, fallecido hace unos años. Pocos meses después, en enero de 2001, apareció una nueva edición, actualizada y aumentada, del libro de Cándido Pozo, Teología del más allá (BAC, Madrid (2) 2001) con más de 600 páginas. Sin duda las obras de Pozo y Ruiz de la Peña constituyen los trabajos más difundidos de la escatología católica posconciliar en lengua española y, además, ejemplifican claramente dos tendencias diversas existentes en la teología católica en este campo, que se reflejan en cada uno de los temas que ellos abordan, en la bibliografía que escogen, en el acento que los inspira, en el lenguaje que utilizan, etc.

El libro de Pozo incluye un nuevo prólogo, conserva íntegro, sin modificaciones, el cuerpo del libro y añade, en comparación con la edición anterior de 1992, un apéndice dedicado a comentar el documento sobre la escatología de 1992 de la Comisión Teológica Internacional (1), las reflexiones de Juan Pablo II en el libro "Cruzando el umbral de la esperanza" y las catequesis del Papa sobre escatología pronunciadas en 1999. Como recuerda el autor, se han vendido más de 18.000 ejemplares de esta obra, lo cual indica su enorme repercusión en el área de lengua española. Sobre este libro parece acertado el comentario formulado por A. Tornos en 1989: "Los planteamientos siguen siendo los tradicionales y en cierta forma 'preconciliares' que ya conocemos. Pero es una obra que interesaría también a quienes no participan de estos planteamientos, pues aporta una enorme riqueza de información sobre publicaciones contemporáneas y sobre aspectos un tanto desatendidos de la tradición eclesial" (2). Sin des-

(1) De quibusdam quaestionibus actualibus circa eschatologiam, Gregorianum 73 (1992) 395-435 (= Algunas cuestiones actuales de escatología, Teología y Vida 33 (1992) 193-223).

(2) Publicaciones sobre escatología 1979. 1989, Miscelánea Comillas 47 (1989) 301$317,307$. conocer estos y otros méritos, el texto refleja en más de un pasaje una tendencia hermenéutica fundamentalista referida a la Escritura y el magisterio (cf. por ej., la reflexión sobre la distinción de las penas del infierno en el NT, p. 453 nota 95; la lectura de la "Benedictus Deus", p. 288s). Sus consideraciones sobre el limbo según "cómo se concibe hoy" (¿quién? pregunto), aunque Pozo no entra en el "valor teológico" de esta doctrina, son igualmente criticables (cf. p. 366 nota 151, 449 notas 86 y 87). El texto dedica también varias páginas a la consideración sobre la naturaleza del fuego del infierno (metafórico o real, aunque no de la misma naturaleza que el fuego terrestre) y a un supuesto "consenso moralmente unánime" sobre la misma; análogamente incluye el tema del "fuego del purgatorio" en la "problemática moderna" sobre el tema (cf. pp. 436, 457ss., 531s.). Esta tendencia se ha plasmado en el documento de la Comisión Teológica Internacional citado, que fue preparado, precisamente, bajo la dirección de C. Pozo. Las críticas que ha recibido son, a mi juicio, atinadas (3).

Algunas características de la nueva edición de La pascua de la creación de Ruiz de la Peña merecen la atención de los lectores. Se trata de una versión "revisada" o, como se expresa en una nota a la tercera edición: "Este texto, que el autor no pudo perfilar en todos sus aspectos, ha sido revisado de acuerdo con la última doctrina de la Iglesia". Se refiere al documento de la Congregación para la Doctrina de la fe, Carta sobre algunas cuestiones referentes a la escatología. Recentiores episcoporum synodi de junio de 1979 dedicado principalmente a la cuestión del "estado intermedio", muy discutida en la escatología católica (particularmente en las décadas del 70 y 80). Aunque no es posible tener una información completamente cierta del proceso que concluyó con la "revisión" del texto del ya difunto Ruiz de la Peña, es público que este libro estuvo a punto de ser sacado de circulación y que, por la intervención de autoridades de primer nivel de la Iglesia española, finalmente se decidió publicar esta nueva edición "corregida".

(3) Cf. J. Noemi, Interrogantes sobre "Algunas cuestiones actuales de escatología”, Teología y Vida 33 (1992) 225-235; P. Phan, Contemporary Context and Issues in Eschatology, Theological Studies 55 (1994) 507-536. 
Sin la pretensión de ofrecer un listado exhaustivo, pongo de relieve algunos de los más importantes cambios introducidos (es el limitado propósito de esta recensión). La mayoría de ellos tienen en común su referencia a la antropología en conexión con el "estado intermedio".

a) En el capítulo 5, "La resurrección de los muertos", afirma la edición de 1996 en la página 166: "Así pues, si el hombre tiene realmente un porvenir más allá de la muerte, este no puede ser el de una subjetividad espiritual y acósmica (tesis de la inmortalidad del alma), sino el de un espíritu encarnado, para el que cuerpo y mundo son otros tantos factores constitutivos de su ser, y no simples complementos circunstanciales de su estar" (cursiva del autor). La versión corregida de 2000 matiza en el paréntesis: "tesis de la exclusiva inmortalidad del alma" (cursiva mía).

b) El párrafo siguiente en la misma página, versión de 1996, comienza así: "Sobre estas bases puede entenderse ya qué quiere decir la fe cristiana cuando proclama su esperanza en la resurrección de los muertos. Con ella no se aguarda la supervivencia de una parte del hombre...". En la nueva versión: "Con ella no se aguarda solo la supervivencia de una parte del hombre...". Se ha añadido el "sólo".

c) En la misma página 166 continúa la versión original: "Al mundo helenizado en que resonó por primera vez el mensaje cristiano de la resurrección, este hubo de resultarle tanto más arduo cuanto que se formulaba en los moldes de una antropología dicotómica del tipo alma-cuerpo. Habría que preguntarse si la situación no sigue siendo (al menos para muchos cristianos, incluidos ciertos teólogos), todavía hoy, la misma”. La versión corregida omite todo el paréntesis y hace un agregado. La oración final queda así: "Habría que preguntarse si la situación no sigue siendo todavía hoy la misma, al menos para algunos autores" (cursiva mía).

d) Al comienzo del capítulo noveno (página 247) se afirma en la edición de 1996: "el hecho de que el fin de la historia (el éschaton, en un sentido muy real) acontece para cada ser humano en su muerte...". La edición de 2000 corrige: "el hecho de que el fin de la historia (el éschaton, en un sentido muy real) comienza para cada ser humano en su muerte...”. (cursiva mía).

e) En el mismo capítulo noveno, sobre la muerte, en el apartado dedicado a la historia de la doctrina hay una omisión (página 258). Después de comentar las opiniones de los Padres de la Iglesia afirma Ruiz de la Peña: "Como se ve, las enseñanzas de los Padres sobre nuestro tema están lejos de ser constantes y claras. Las indecisiones en punto de tan gran importancia se explican cuando se tiene en cuenta que la doctrina de la retribución inmediata suscita dos serias dificultades: una de carácter antropológico y otra de índole teológica. El problema antropológico reside en la dificultad de concebir como sujeto apto de la retribución no al hombre enero, sino a una de sus partes (el alma); hemos visto cómo, de San Justino a San Agustín, esta tesis es sentida por los testigos de la tradición como próxima al dualismo herético. Ante la depreciación de lo corporal, tan influyente en su medio ambiente, desencarnada como sujeto de la consumación escatológica. La dificultad teológica está en el peso que ejerce sobre los Padres la importancia de los acontecimientos finales -juicio, resurrección-, tan insistentemente inculcada por la Escritura, así como la índole comunitaria de la vida eterna; una bienaventuranza plena antes del éschaton ¿no reduciría severamente la trascendencia de este?" La versión revisada, además de suprimir los renglones escritos en letra cursiva, comienza así: "Como se ve, las enseñanzas de los Padres sobre nuestro tema se debaten entre el reconocimiento de una retribución inmediata y la necesidad de reconocer también la dilación de la retribución plena. Las indecisiones en punto de tan gran importancia...".

f) El último punto de este mismo capítulo sobre la muerte se detiene específicamente en la cuestión del "alma separada" (páginas 276 a 278). Se titula: “Alma separada en un estado intermedio?" El apartado comienza aclarando que el tema está ya bastante agotado (afirmación que podría discutirse): "A decir verdad, la discusión ha llegado a un punto muerto, sin que sea previsible que aparezcan nuevas aportaciones capaces de reactivarlo: las distintas posiciones al respecto han explorado todas las posibilidades; ninguna de ellas, además, ha logrado imponerse a la otras. Estamos, pues, ante una cuestión agotada; en las últimas publicaciones sobre el tema escatológico se percibe una neta sensación de cansancio ante un problema que, en resumidas cuentas, 'pertenece al ámbito de la pura especulación'. Así las cosas, bastará dedicarle las siguientes breves reflexiones". Las frases escritas en letra cursiva aquí han sido omitidas en la nueva versión.

En las páginas 277 y 278, la edición de 1996 formula cuatro puntos, de los cuales el primero ha sufrido una corrección, los tres restantes han desaparecido.

En el primer párrafo, el a), se ha eliminado la frase que aquí reproducimos en letra cursiva: “ ¿Se da una situación de alma separada a lo largo de un período temporalmente extenso (el que se intercalaría entre la muerte y la resurrección)? Tal ha sido la interpretación tradicional, tenida por válida hasta el primer tercio de nuestro siglo, tanto por católicos como por protestantes, pero en la que hoy se detectan serias dificultades".

El párrafo segundo, el b), ha sido eliminado. Afirmaba: "Ni la revelación ni el magisterio eclesial aportan elementos resolutivos; la cuestión debe considerarse, pues, como teológica, no dogmática. El escrito de la Congregación para la Doctrina de la $\mathrm{Fe}$ sobre algunas cuestiones escatológicas contiene cier- 
tas precisiones al respecto. Tales precisiones no parecen incompatibles con alguna de las teorías presentadas como alternativa a la tesis tradicional. De todas formas, dado el nivel magisterial de este documento, sus observaciones no pueden aspirar al rango de doctrina vinculante; tendrá a lo sumo un carácter orientativo, que debe ser ponderado por los teólogos, pero que no puede considerarse como dirimente".

El tercer párrafo, también eliminado de la edición de 2000, refiere a dos de las teorías acerca de la naturaleza del estado intermedio, la primera defendida por Boros, Schoonenberg, Martelet, Boff y el último Greshake, la segunda, por el mismo Ruiz de la Peña, además de Semmelroth, Biffi y el último Lohfink: “c) Tanto la tesis de una resurrección, por así decir, bifásica (incoada en la muerte, consumada en el éschaton) como la que sostiene que muerte y resurrección son dos acontecimientos distintos y sucesivos, mas no necesariamente distantes (esto es, separados por un continuum temporal), respetan los datos dogmáticos involucrados en el problema. Su plausibilidad puede ser discutible; no lo es su ortodoxia. Quien opine lo contrario, debería asumir la carga de la prueba".

El cuarto párrafo de la edición de 1996 (página 278), ausente en la nueva versión, afirmaba: “d) El cuestionamiento de la tesis tradicional es hoy ampliamente mayoritario en la teología católica. Atribuir este hecho a una información deficiente, a una evaluación incorrecta de los datos o, lo que es peor, a un progresismo irresponsable, es tan gratuito como injusto. El problema del estado intermedio ha interesado a la teología contemporánea porque lo que ahí se juega, en última instancia, es el grado de convicción y coherencia con que la antropología cristiana sostiene la identidad del hombre como unidad sustancial de espíritu y materia. Las teorías alternativas a la doctrina tradicional quieren mantener esta verdad del hombre, para hacer así creíble no solo la afirmación de la unidad psicosomática, sino también la esperanza en la supervivencia del ser humano en su identidad e integridad".

En lugar de estas conclusiones de Ruiz de la Peña, en la versión de 2000 se reproduce parte del documento de la Congregación para la Doctrina de la Fe de 1979, introducido por la siguiente oración: "Este documento tiene que ser tenido en cuenta por los teólogos". Llamativamente la presentación del documento magisterial que se hace comete un grave error, a mi juicio, por lo menos tan "grave" como el que pretende "revisar", al incluir la expresión "tiempo", ausente, y no por casualidad, en la versión oficial vaticana. Es la interpretación de Pozo (4).

(4) Escribe el teólogo de Granada, comentando el texto de la Congregación: "La proposición $5^{a}$ señala la parusía como acontecimiento no solo distinto, sino separado temporalmente de la muerte del individuo y de la situación inmediatamente posterior a la muerte", Teología del más allá, 300.
Concluir de este recensión que su autor comparte la posición, ahora "revisada", de Ruiz de la Peña constituye una deducción infundada.

Carlos Schickendantz

PEDRO URBANO LOPEZ DE MENESES, Theosis. La doctrina de la Divinización en las tradiciones cristianas fundamentos para una teología ecuménica de la gracia, Ediciones Universidad de Navarra, S.A. Pamplona Facultad de Teología Universidad de Navarra "Colección Teológica" 104, Primera edición: Noviembre 2001, Pamplona, España, 408 pp.

Al abordar el tema importantísimo de la theosis, la "divinización del hombre" como una propuesta ecuménica, el presente estudio promete un aporte novedoso y desafiante para el preciso momento histórico que está viviendo el diálogo ecuménico. Toda la discusión teológica y pastoral se está concentrando en la "Declaración sobre la justificación”. Esto conlleva implícitamente la pregunta ¿más allá del tema espinudo de la justificación habrá otro enfoque que una o desuna a los cristianos de las diversas confesiones? Una alternativa sugerente pretende proponer este estudio de doctorado de Pedro Urbano López de Meneses, de la Universidad de Navarra, que saca a la luz una temática común a todas las confesiones cristianas, previa a las grandes divisiones del cristianismo. He aquí la relevancia innegable del presente estudio. De hecho, su autor piensa que "detrás de un estudio comparado de la divinización, se esconde la posibilidad de construir una antropología abierta a las diferentes sensibilidades espirituales del horizontes cristiano" (p.22).

El Prólogo y la Introducción explican el propósito de la extensa elaboración de una importantísima temática de la Teología de la Gracia, entroncado con la Pneumatología, como lo resalta el breve Status quaestionis desde sus fundamentos bíblicos hasta los estudios más recientes. La elaboración más específica, sin duda, se produce en el período patrístico, en estrecha interrelación con las grandes discusiones cristológicas, sintetizado en el axioma: "Dios se ha hecho hombre para que el hombre se haga Dios". Como se trata de una elaboración previa a la Reforma y Contrarrefor$m a$, el recuerdo del fundamento común de una doctrina tan importante, constituirá un fundamento sólido para discutir aspectos que posteriormente llevaron a la separación. Sin embargo, pesa por igual la refutación actual del mencionado axioma de parte de H. Küng, quien sostiene que al hombre de hoy no le interesa el "llegar a ser Dios", sino el "hacerse hombre". El verdadero contenido de la divinización, de hecho, es complejo. Así lo 
permite apreciar el contenido, que emerge de este libro, a través de sus cuatro secciones, subdividas cada una en sus capítulos respectivos.

La Sección Primera está dedicada a la Tradición del Oriente cristiano. Explica, en tres capítulos: la "theosis" en la patrística oriental, la teología palamita de la divinización del hombre y la divinización en la teología ortodoxa contemporánea. Sugerentes son los títulos tales como Pneumatoforos, La mística de la Luz y el ZOON Theoumenon, pues iluminan el desarrollo claro y profundo del complejo contenido desde sus facetas más propios. En efecto, el primer Capítulo sintetiza los aspectos fundamentales de la divinización tales como "las raíces culturales, teológica y religiosas de la doctrina sobre la divinización", su articulación en el Antiguo Testamento, la religión y filosofía griega, su comprensión como antropología mística del Oriente, la gnóstica de Clemente Alejandrino, la recapitulación por Ireneo, y sobre todo la presencia del Espíritu Santo en la reflexión antropológica de los Padres Capadocios para desembocar en la Teognosis apofática. El segundo Capítulo explica la teología de Palamás respecto de la divinización como testimonio de la tradición oriental, sobre todo, a partir del juego de la luz, que se especifica en las energías increadas y su interrelación con la gracia deificante. El tercer capítulo aborda la divinización en la Teología ortodoxa contemporánea, donde la theosis se interrelaciona con la kenosis del Verbo de Dios y la pneumatologia.

La Sección Segunda expone la Tradiciones Teológicas del Occidente Medieval a través de cinco capítulos, con las siguientes temáticas: La deificación en la antropología agustiniana, La "theosis" en la teología de Juan Escoto Eriúgena La teología monástica de la unión con Dios, La teología escolástica de la divinización, La antropología mística de fa deificación. Desarrolla, entonces, los títulos I. Simul Iustus et deificatus, II. La ciencia de la theosis, III. Unus spiritus cum Deo, IV. Participes de la naturaleza divina y V. El fondo del alma. A través de los aportes de pensadores como Agustín, Juan Escoto Eriúgena, san Bernardo y Guillermo de St.Thierry, Pedro Lombardo, san Buenaventura y Tomas de Aquino, M. Eckhart, J. Ruusbroec y J.Taulero, va emergiendo una riqueza teológica insospechada que, más que perteneciente al Dogma, se puede creer propia de la mística, en un sentido específico. De hecho, sin embargo, esta riqueza atestigua los grandes problemas de la relación entre Dios y el hombre, que desembocan en un callejón sin salida, si concurren en un mismo nivel, pero que se revelan en su verdad profunda a partir de la desproporción que proviene de la anticipación de Dios para con su criatura. Ella, pues, solo encuentra su realización en la vuelta gozosa y divinizante de flujo y reflujo a su origen trinitario, para la unidad de un solo Espíritu.
La Sección Tercera está dedicada a la Tradición Teológica Protestante, describe en tres capítulos:

La teología de la "theosis" en Lutero, La crítica de la "theosis" en el protestantismo liberal, El protestantismo contemporáneo ante la deificación. Bajo significativos títulos, tales como Christus in Fide adest, La sombra del helenismo y La elevación del hombre. cada apartado ofrece una visión panorámica de los aportes de Lutero, del protestantismo liberal (Hegel, A. Ritschl y A. von Harnack) y del protestantismo contemporáneo, sobre todo, en lo que se refiere a K. Barth, R. Bultmann y P.Tillich. No cabe duda, que resalta aquí el fuerte cristocentrismo de la mística protestante, como también su enfoque forense. Una dialéctica de gran vitalidad espiritual, pero articulado con conceptos diferentes.

La Sección Cuarta presenta una visión nítida de la Tradición Católica Postridentina, en tres capítulos, que explican La teología postridentina de la Gracia; El Espíritu Santo y la divinización en la teología de renovación y Humanismo y divinización en la teología contemporánea. Los títulos de estos capítulos son los siguientes: Effectus Formales Gratiae; El Sello divino del Alma; Humano, demasiado humana. Aquí se puede apreciar, en primer lugar, la precisión conceptual del escotismo postrindentino y de los tomistas, en especial de Suárez. Pero, luego, emerge aquella la profundidad teológica, ligada a nombres como Möhler, Staudenmaier, Scheeben, inolvidable e inapreciable en sus efectos sobre el Vaticano II. Pero también surgen, finalmente, los ecos de la discusión postconciliar, que dejan aquel sabor amargo cuestionador de un enfoque demasiado humanizante, que ejemplifica el aporte de J.B.Metz.

Sin duda, estamos aquí ante un trabajo laborioso, claro y afinado en sus diversas contribuciones y enfoques específicos, sobre todo, en lo que se refiere a la teología ortodoxa y luterana. También resultan muy sugerentes los aportes de autores medievales como Bernardo y Guillermo de St. Thierry o de Scheeben y Barth. Sin embargo, toda la argumentación del libro se mueve dentro del amplio margen de generalidades bastante conocidas. En este sentido sorprende, sobre todo, el espacio reducido y la poca atención que recibe el período fundante de la temática de la divinización, la patrística. Parece que el autor pretende encontrar el "consenso diferenciado", a modo de la Declaración Conjunta, sin tomar en cuenta las formas propias del pensar y conceptualizar, que hacen surgir los diversos aportes. De ahí que la agradable lectura de un contenido bien presentado deja la impresión que falta mayor análisis crítico, para que los resultados tengan un impacto convincente para el diálogo ecuménico. Pues el tratamiento de la temática propuesta conlleva, según mi modo de ver, una 
tendencia a uniformar, allí donde la diferencia de las "sensibilidades espirituales", tal vez aportaría mayor luz. Pues ¿no es precisamente la diferencia en la unidad el signo de máxima unión, a modo de la Trinidad? Lo cual no significa resaltar la diferencia a toda costa como lo hacen, con preferencia, las confesiones protestantes, sino tomar en serio su fuerza unitiva en cuanto constituyente de aquella unidad, que brota del Amor.

\section{Anneliese Meis}

CODA PIERO, "El Agape como Gracia y Libertad. En la raíz de la teología y la praxis de los cristianos". Editorial Ciudad Nueva, Madrid 1996, 192 pp. Título original "L’agape come grazia e libertà”, Cittá Nuova Editrice, Roma 1994.

El ensayo de Piero Coda se presenta como "un primer y original intento de lectura teológica del ágape como clave interpretativa sintética del misterio cristiano y de su realización en la historia". Este texto aborda la literatura teológica y filosófica para retornar a lo bíblico. La primera carta de Juan; la interpretación de Pablo y del evangelio de Juan; y finalmente trata los Hechos de los Apóstoles. El último capítulo presenta algunas consecuencias cuando el amor configura la identidad y la misión de la Iglesia actual.

En la introducción se estudia el origen, los recorridos y las perspectivas de una teología renovada del ágape. El autor comienza exponiendo algunas de sus motivaciones: un congreso sobre "La caridad como hermenéutica teológica y metodología pastoral" y el Concilio Vaticano II, que supo situar el ágape como uno de los pilares de su magisterio tanto en la teología moral como desde la perspectiva cristológico-trinitaria y eclesiológica.

Después del Vaticano II la originalidad del ágape cristiano se tematiza en dos líneas. Una de carácter teológico, lo cristológico, la relación entre amor a Dios y al prójimo, y lo eclesiológico; y la otra de carácter práctico que une lo teológico y pastoral. Hoy se propone la recuperación del ágape como lo central en el ser y en el actuar de la Iglesia. Para esto se anima a volver a "las fuentes bíblicas del evangelio de la caridad" (13) y a la identidad de la Iglesia desde el amor.

El primer capítulo (15-28) trata sobre "El ágape y su fortuna terminológica y semántica" en cuatro epígrafes.

El amor es una experiencia universal, dentro de la cual el cristianismo aporta una originalidad. El amor como autocomunicación de Dios Padre en Cristo por medio del Espíritu Santo. Esta originalidad tiene dos tensiones: reducir lo cristiano a lo humano y separar lo cristiano y lo humano. Se necesita claridad a nivel terminológico y semánti- co; para ello se estudia el mundo clásico griego y latino, el horizonte veterotestamentario y el neotestamentario.

El autor estudia la dialéctica éros/ágape en la interpretación de A. Nygren. Hace una síntesis y una puntualización crítica. Para este autor “... el éros designa la vía que va del hombre hacia Dios; el ágape, por el contrario, la que desciende de Dios hacia el hombre en Cristo. (...) el ágape es el don de la salvación hecho por Dios al hombre; mientras que el don que, en respuesta, el hombre hace de sí mismo a Dios es la fe (pistis)" (18).

El tercer aspecto que propone es la necesidad de una profundización bíblica y teológica. Se trata de ver la pluralidad de significados de la noción de amor en el pensar greco-helenístico; la raíz veterotestamentaria del mensaje cristiano; el significado neotestamentario de ágape; y la traducción lingüística y semántica del ágape del NT por la caritas de la teología latina (agustiniano-tomista).

En el griego clásico y la Koiné se diferencian cuatro palabras: storgé, éros, philía y ágape. Storgé como amor de afecto instintivo basado en la consaguinidad, es independiente del valor de lo amado. Éros se refiere a amor como deseo vehemente, frecuentemente vinculado a lo sexual. Philía es el amor como amistad libre y gratuita pero determinado por el valor del sujeto amado. El término ágape no está en el griego clásico como sustantivo, este amor es una relación de privilegio por una persona que responde con el reconocimiento, en ambos es libre, se traduce al latín por diligere.

En el hebreo veterotestamentario aparecen los términos ahabâ, hésed, rahamím. Ahabâ tiene tres acepciones: el amor de tipo sexual; el amor de consaguinidad y de amistad; y el amor como norma ético-social que es lo novedoso respecto al mundo griego. Hésed como misericordia (jurídico) es una deliberación consciente y entraña derechos y deberes, significa bondad, compasión, perdón y se fundamenta en la fidelidad. Rahamím es la compasión por los sufrientes, tiene un colorido femenino. Lo novedoso respecto a lo griego-helenístico es que estos términos expresan la relación de Dios con su pueblo y la relación del hombre con el hombre.

A continuación estudia el griego de los LXX y del Nuevo Testamento. Se detecta que en la traducción griega del Antiguo Testamento por los Setenta, la palabra ágape traduce ahabâ y la palabra éleos expresa hesed y rahamín. En el Nuevo Testamento ágape sintetiza los tres términos hebreos del AT, y expresa el amor de Dios por su pueblo que llega a culmen en Cristo.

En cuarto lugar el latín cristiano acuña el término $c(h)$ aritas para significar el amor específicamente cristiano. La Vulgata usa también dilectio cuando ágape tiene el destinatario bien especificado y cobra un matiz de afecto. Afirma Coda: "Por tanto, el latín $c(h)$ aritas representa no solo la síntesis ya presente en el griego neotestamentario 
ágape (como amor y misericordia, en la unidadpluralidad de significados que encontramos en el Antiguo Testamento) y sobre todo la novedad cristológica, sino también la estructura del acontecimiento salvífico expresada por el término paulino y joaneo charis, que indica la benevolencia, la gracia, no merecida sino otorgada solo por Dios Padre como don del Espíritu Santo a través de la cruz de Cristo. (...) es evidente un gran proceso de profundización semántica del concepto de amor, (...), que se expresa también en una notable y significativa creatividad terminológica" (28).

Las ideas centrales del capítulo segundo (2950), que titula "Amor al prójimo y amor de/a Dios en el Antiguo Testamento", se pueden sintetizar del siguiente modo.

El amor al prójimo es un precepto ético-religioso que supera lo electivo. Los tres principales cuerpos legislativos del Antiguo Testamento van radicalizando progresivamente la exigencia de amor al prójimo hasta hacerlo como a uno mismo. "El horizonte del éxodo y de la creación es, pues, en último término, lo que funda el precepto del amor al prójimo en la perspectiva veterotestamentaria, y lo que la distingue del horizonte griego" (34).

De aquí deriva el amor al pobre en su significado teológico y en la reglamentación práctica a nivel socioeconómico que se concreta en "una 'utopía reguladora' llamada a transformar continuamente y desde dentro la vida social del pueblo elegido, para hacerle conforme con el designio de Dios" (37). Esto es lo que los profetas proclamarán como un "nuevo orden de cosas, que es creado por Dios y que desborda derecho y justicia" (39). Así el término justicia se emparienta al de amor, y la responsabilidad por la justicia se enraíza en un corazón nuevo. Dios interioriza en el corazón del hombre el amor y es como un trasplante del modo de ser y de obrar de Dios en el sujeto.

Finalmente se presenta a Dios como sujeto del amor y como objeto de amor. Dios en la liberación de Egipto y en la Alianza sinaítica manifiesta su Nombre revelado a Moisés: el Dios de la santidad y los celos (Ex 19, 24.34), de la misericordia y de la fidelidad (Ex 34, 6; 2 S 2, 6; etc.). El objeto de este amor es el pueblo en su conjunto. El amor de Dios por Israel nace de la elección, es gratuito y fiel; paternal y esponsal. Dios ama de modo personal al hombre invitándolo a la intimidad esponsal: de aquí surge el amor entre los hombres, así el amor humano expresa el amor divino. El hombre ama con un amor de respuesta que es personal y totalizante, que implica toda la personalidad, lebah (corazón) y nefesh (alma). Coda se expresa así: "en el amor a Dios tiene más importancia que el sentimiento la eficacia y la coherencia ética de vida del hombre. (...) El culto mismo en que se expresan, (...), no tiene valor si no es verificado por la justicia y por la intención del corazón. Y es precisamente sobre esta intención del corazón sobre la que, junto con la dimen- sión de justicia propia del amor a Dios, insisten, con el Deuteronomio, los profetas postexílicos. En efecto, la promesa de la nueva Alianza concierne en primer lugar a la relación del hombre con Dios, la interiorización y la purificación, por medio del don del Espíritu de Yahvéh, de la relación de amor, de fidelidad y de justicia con Él. Más aún, se podría decir que, cuanto más avanza Yahvéh en la revelación de su rostro y de su designio de salvación (cuanto más, por así decir, nos hace penetrar en el abismo de su Vida íntima), tanto más debe el hombre dejar espacio en sí a Su acción, debe cavar en sí un abismo capaz de acoger el don de Dios ("el abismo llama al abismo", cantan los Salmos [cf. Sal 41, 8]), y de devolverle, desde el corazón, desde el fondo de sí, toda su existencia. Es por esto, en fin, por lo que el mandamiento del amor (...) no puede consumarse en plenitud y para siempre en la historia, y por tanto invoca un cumplimiento que no puede no ser sino metahistórico y definitivo" (49-50)

En el tercer capítulo (51-80) el autor desarro1la "Una perspectiva sobre el Nuevo Testamento: el ágape en la 1 Juan". El ágape sintetiza el proyecto de Dios en la historia hacia lo definitivo a través de Cristo.

Se estudia la primera carta de Juan desde el tema del ágape. Primero como "categoría sintética para anunciar el acontecimiento cristológico como autocomunicación de Dios Padre en el Espíritu a los hombres; y, en un segundo tiempo, la categoría sintética para expresar la respuesta de fe y la característica fundamental y unitaria del ethos y de la praxis cristiana" (55).

El ágape como autocomunicación de Dios significa que: el amor está unido a la cruz (dimensión cristológica); que Dios sacrifica lo más querido porque Él es amor (dimensión teológico-trinitaria); el Espíritu enlaza al amor entre el Padre y el Hijo, al hombre y al cosmos (la pneumatológica); el amor entre los hombres lleva a plenitud el ágape como vida de Dios que desborda el corazón de los hombres (la dimensión antropológica).

El movimiento descendente, teocéntrico, cristológico y pneumatológico del ágape se ve correspondido, en la primera carta de Juan, con el ascendente, antropológico-eclesial, ético-práctico, de la respuesta del hombre.

La fe en Cristo es creer en el ágape. La fe y la caridad van unidas (Cf. 1Jn 3, 23), Dios ama y nosotros al amar continuamos en horizontal el amor vertical que Dios ha mostrado. Así se enlazan la ortodoxia (confesión de fe cristológica) y la ortopraxis (amor recíproco). El creer y el conocer se complementan (Cf. 1Jn 4, 14-16; 3, 1; 4, 7b-8a). El conocimiento remite a la vida en comunión, a una relación de esponsalidad. Coda afirma: "La novedad cristiana se inserta, pues, ciertamente, en la tradición del Antiguo Testamento: el conocimiento de Dios se pone en marcha a partir de la automanifestación de Dios en la historia de 
Israel y se realiza en la praxis de "justicia". Es específicamente cristiano el hecho de que el rostro de Dios se revela de modo singular y absoluto en el rostro de Jesucristo, y es precisamente esta manifestación escatológica del rostro de Dios como amor en Cristo Jesús la que, suscitando la fe, suscita también la reciprocidad del amor como característica típica del ethos cristiano" (71).

Fe y ágape son distintos y se copertenecen. En la relación del hombre con Dios, "fe y ágape son indisolubles. La fe (...) (es) receptividad del hombre en relación con el ágape de Dios" (73). Esta recepción del ágape se muestra en la falta de temor y en la plena confianza y libertad. Solo el ágape puede suscitar la certeza de la fe. En esta relación la fe preserva al amor de confusión y tentación totalizante, ya que toda relación debe estar marcada por el amor de Dios y debe traducirse en amor con y entre los hermanos.

En la relación del hombre con el hombre: a) se ama al otro desde la relación que se tiene con Dios; b) se ama al hermano al estilo de Jesús, ofreciendo la vida que es el fundamento del ágape cristiano; c) el amor al hermano es concreto, se hace en la cotidianidad de la vida; d) el ágape tiene estructura pascual, hace pasar de la muerte a la vida; e) el ágape es recíproco; f) el ágape tiene una dimensión pneumatológica (1Jn 4, 13).

En síntesis, la carta presenta el "ágape a la luz del acontecimiento cristológico en su doble y complementaria dimensión: la teológico-teocéntrica en perspectiva trinitaria y la antropológicaeclesiológica en la perspectiva del ethos y de la praxis de la reciprocidad que hay que extender de modo universal". El ágape se sintetiza en $c(h)$ aris (el primer movimiento, gracia) y en libertad y unidad (el segundo movimiento). En esta carta se asume el ágape como categoría hermenéutica central del cristianismo.

"El ágape en el kérigma, en la praxis y en el destino del Jesús histórico", en los sinópticos, es el contenido del cuarto capítulo del libro de Coda (81-113). A continuación, en el capítulo cinco, tratará el ágape en la relectura postpascual del acontecimiento de Cristo (Juan) y en la praxis del acontecimiento Iglesia en la comunidad apostólica (cartas de Pablo y Hechos de los Apóstoles).

Este capítulo aborda el mensaje y la praxis de Jesús. Se pone de manifiesto su autoconciencia y su intención respecto al significado de su mensaje sobre el amor. Jesús expresa su autoconciencia en dos dimensiones: su kerigma, su praxis y su persona muestran el rostro del amor del Padre para con los hombres, y en segundo lugar Jesús muestra un rostro inédito en la relación del hombre con Dios y del hombre hacia los demás hombres. Para Coda, Jesús es "el anuncio y el testimonio escatológico del amor de Dios al hombre y del amor del hombre a Dios y al otro hombre" (82).

El corazón de la experiencia religiosa de Jesús acontece en esta relación, Dios es Padre y Él es Hijo. De aquí arranca su mensaje y su praxis de amor. Para Jesús la fe hebrea en Dios (Dt 6, 4s) queda vinculada con el amor al prójimo ( $\mathrm{Lv} 19$, 18), esto es original y decididamente de Jesús. Esta vinculación nace de su experiencia de relación con el Padre: relación de comunión (Abbá); distinción entre los dos (alteridad); reciprocidad que es expresión de perfecta unidad en la distinción; y, finalmente, esta relación de alteridad/reciprocidad se da en el Espíritu.

El mandamiento del amor a Dios va parejo a la filiación. El amor a Dios es respuesta a la paternidad de Dios para el hombre. Jesús hace la mayor experiencia de la paternidad de Dios en el fracaso. En el dar la vida de Jesús se muestra la unión con el Padre. El mandamiento del amor al prójimo y su nueva centralidad, Jesús lo formula en positivo (Mt 7, 12), lo hace de modo exclusivo (único mandamiento), tomando la iniciativa (samaritano), y cambiando el corazón (Mt 5, 21s). Con Jesús la llegada del Reino irrumpe en la historia. El amor al prójimo es de la misma naturaleza que el amor a Dios. Se pertenece al hermano como se pertenece al propio Dios.

En la relación de Jesús con los hombres destacan dos realidades. Los pobres son los destinatarios privilegiados del anuncio del Reino. Esta preferencia se justifica en cuatro dimensiones teológicas. La dimensión universalista, el pobre interpela a la conciencia humana. La dimensión teológico-teocéntrica, Dios que es Misericordia y Amor no puede no privilegiar a los últimos, ya que su amor es verdadero, realista y eficaz. La dimensión cristológica, Dios ama a los pobres y se hace uno de ellos y desde dentro los libera. La dimensión pneumatológica, es desde "esta identificación de amor como Dios transforma la situación de los pobres, (...) el Espíritu del Resucitado se convierte en el espacio de la nueva tierra prometida" (94). La segunda realidad, en la relación de Jesús con los hombres, es que la llegada del Reino se presenta como comensalidad con los excluidos. Jesús come con los desposeídos como signo de la misericordia que invita a la conversión y al perdón (Mt 22, 1-14; Mt 9, 10-11; Lc 19, 110). Jesús se muestra como el rostro del Padre misericordioso para todo el pueblo.

En la relación con el prójimo, en la perspectiva de la llegada del Reino, Jesús propone: "la universalidad, la dinamicidad, la concretez, y la noviolencia activa" (97). La primera característica se soluciona respondiendo la pregunta que Jesús plantea: ¿quien es el más próximo al necesitado? (Lc 10, 29-37; Mt 25, 31-46). "Se puede concluir que el ágape -presencia de la misericordia de Dios en el corazón del hombre- es un dato antropológico universal, de una antropología abierta a la presencia y a la acción de Dios en cada persona por obra del Espíritu Santo (GS 22; LG 16), si bien llega a su pleno despliegue solo en relación a la fe en Cristo" (99). 
La reciprocidad del ágape se expresa en la relación hombre-mujer, tanto en Jesús como en la Iglesia apostólica, se plantea como el arquetipo de la relación de amor al prójimo. En la praxis y en el kérigma de Jesús la mujer y el varón son vistos desde la igualdad del principio (Mt 19, 3; Mt 5, 28) y desde la verdad enfrentando la hipocresía (Jn 7, 53-8, 11; Jn 4, 1ss). La mujer ante Jesús se encuentra reconocida, amada y liberada (Lc 7, 47; Mc 14, 9; Mt 23, 13). En la cruz están las mujeres. El resucitado se aparece en primer lugar a una mujer, ¡novedad revolucionaria! Al lado de esto, la comprensión de la Iglesia apostólica mira el ser del hombre y de la mujer como recíproco don-desí (Gá 3, 28; Ef 5, 21-33).

La concretez del mandamiento del amor al enemigo supera la ley del talión (proporcionalidad en la justicia y limitar la venganza). Jesús propone en positivo el amor a los enemigos. Es el mandamiento de la llegada del Reino; expresión de la gratuidad. La no violencia se muestra en la praxis jesuana del Reino como "praxis del Cielo", es la utopía encarnada aunque de modo germinal. Se encarna la vida que se vive en el cielo.

En el último apartado trata la ley de la comunidad mesiánica como amor fraterno y diaconía. El destinatario del amor al prójimo supera lo puramente intracomunitario, provocando un vuelco escatológico (comunidad no autoritaria, no solo masculina). El signo de la llegada del Reino se resume en el amor que implica dar la vida (Mc 8, $35 \mathrm{ss}$ ). Ambos elementos expresan la autoconciencia de Jesús ante la muerte que Él "elige libremente soportar, en obediencia" al designio salvífico del Padre y la muerte como don de sí que es la dimensión constitutiva del amor.

El capítulo quinto recoge "La relectura cristológica y trinitaria de Pablo y de Juan y la praxis de la Iglesia en los Hechos de los Apóstoles" (114-135). La comunidad de Jesús anuncia la fuerza del amor presente en la resurrección. El ágape derriba lo viejo y anticipa lo definitivo. Es la experiencia de lo nuevo (Gá 3, 26-28) y la edificación en la historia de lo único que permanece, el amor (1Co 13, 2-8).

Se estudian tres temas: el ágape como cumplimiento de la ley en San Pablo; la dinámica pascual y trinitaria del ágape en San Juan; y la comunión de bienes en los Hechos de los Apóstoles como realización de la llegada escatológica del Reino.

San Pablo presenta el ágape como la plenitud de la Ley, como don del Espíritu y bajo la dinámica de "kenosis".

Lo nuevo brota del ágape de Cristo que se manifiesta en la cruz del Señor (2Co 5, 14-17 fórmula sintética de lo que es el ágape evangélico). El vaciamiento de Cristo es la norma y fundamento para el comportamiento moral (Gá 5, 14; Rm 13, 8-10). El concepto paulino de ágape tiene dos connotaciones: la gracia-libertad como don del Espíritu de Cristo en el corazón de la persona y kénosis como clave existencial de la vida de la comunidad en el ágape.

Afirma Coda: "El ágape, es ley de libertad, porque (...) los hijos, en el Hijo, por obra del Espíritu Santo $(\mathrm{Rm} 5,5 ; 8,1 \mathrm{ss})$, responden al ágape del Padre, viviendo la plenitud de la relación trinitaria $(2$ Cor 13,13$)$ ya en esta vida, aunque en tensión hacia la consumación escatológica (Gá 4, 6, el Espíritu de su Hijo en vuestros corazones clama ¡Abbá, Padre!)" (121).

El ágape es releído como pro-existencia kenótica desde el texto de Flp 2, 5-11. El autor rescata tres elementos: 1 la humildad como concreción del ágape en el contexto comunitario; 2 Cristo es acontecimiento de humildad-kénosis y esto requiere vaciamiento de sí; y 3 el misterio trinitario del recíproco y total don de amor abierto a la dinámica del acontecimiento pascual. Este último elemento es el trasfondo para leer la kénosis como paradigma antropológico del ágape.

San Juan interpreta el acontecimiento pascual como "supremo acontecimiento de amor y revelación de la "estructura" de reciprocidad trinitaria y de efusividad del ágape" (123). El perder la vida y la Eucaristía muestran la identidad de Jesús como Hijo. El ágape del Padre por el Hijo se muestra en este mandato de dar la propia vida para recuperarla (Jn 10). Esta donación señala la fecundidad del ágape (Jn 12, 24-25); la última cena es signo del ágape como don de la vida hasta el final (Jn 13, 1).

El segundo elemento de la teología joánea sobre el ágape es la relación entre el conocimiento del misterio de Dios, como Ágape trinitario, y la vida de los discípulos como amor recíproco (Jn 13, 34-35). La credibilidad de la fe cristiana (Jn $17,21)$ pasa por la alteridad en la reciprocidad del hombre con Dios y entre los hombres. La dinámica kenótica (Jn 15, 12-13) entra en la reciprocidad a la luz de la Pascua. La relación entre amor y muerte es porque el amor es don-de-sí, y la muerte, vivida como ofrenda, es la posibilidad del don del ágape. En la relación de amor en la trinidad así sucede "entre Padre, Hijo y Espíritu Santo, donde Cada Uno de los Tres vive ("es") simultáneamente en Sí y en el Otro gracias a la muerte ("no es") a Sí como realidad autosuficiente y cerrada en sí. Esta unidad perfecta en la alteridad vivida como reciprocidad es posible solo en Dios" (126). Pero por la encarnación, la muerte y la resurrección, y la efusión del Espíritu Santo se convierte en vocación para cada persona humana.

Un tercer elemento de la teología joánea es la unidad, consumación trinitaria del ágape reciproco. Jn 17 resalta la unidad como perfección del ágape recíproco. El ágape que el Padre ofrece al Hijo y este a los discípulos, ocasiona una interioridad entre Dios y los discípulos tal que estos moran en Dios y Dios en ellos (Jn 14, 23 y Jn 15, 9 permanencia en el amor). La reciprocidad del amor y la mutua inhabitación entre el Padre y el 
Hijo se realiza a través del Espíritu. El ágape es la expresión de la unidad y tiende a la unidad.

En síntesis, el evangelio de Juan también presenta el ágape como plenitud de la Ley (Jn 14, $21.23 ; 15,9-11)$. Otra dimensión del cuarto evangelio es la de "philía" (Jn 15, 15; 21, 15ss) que muestra el ágape como superación del miedo (temor servil).

El Nuevo Testamento (teniendo en cuenta a Pablo, el cuarto evangelio y la primera carta de Juan) presenta el ágape "configurado cristológicamente como Ley del Espíritu en el hombre y entre los hombres, es la categoría que resume la ortodoxia y la ortopraxis cristiana que remiten la una a la otra y se verifican recíprocamente, y que tienen su característica formal en la reciprocidad trinitaria del Padre y del Hijo en la efusividad del Espíritu y en la kenoticidad pascual" (129).

Coda finaliza el capítulo estudiando el significado mesiánico de la comunión de bienes en los Hechos de los Apóstoles desde los dos sumarios: Hch 2, 42-48 y Hch 4, 32-37.

La koinonía, es signo mesiánico del don escatológico del Espíritu Santo. La comunidad vive la comunión en los bienes escatológicos de la salvación por el don del Espíritu Santo. En el primer sumario (Hch 2, 42-48) se describe el misterio de la Iglesia. Al compararlo con el capítulo 4, se destaca que la comunión es compromiso por la fraternidad y evidencia la vida profunda de la Iglesia (un solo corazón). Unidad para la comunión.

La utopía de la comunión de bienes no pretende el despojo de los bienes sino que no haya pobres. El acontecimiento de la comunión de bienes es don del Espíritu que cambia los corazones y opera una socialidad nueva marcada por el ágape. La comunión en el amor crea relaciones que se manifiestan a nivel social incluso en la vida económica. La comunión de bienes es espontánea, personal y libre.

Esta práctica conduce a la organización de la catolicidad manifestada en dos signos. La institución de los "siete" retoma una praxis asistencial precedente en la comunidad apostólica y primitiva; perfecciona y desarrolla la estructura ministerial para responder a las necesidades; se institucionaliza lo espontáneo para eliminar la discriminación; la diaconía caritativa pertenece, de forma ministerial, al compromiso de la comunidad cristiana. El otro signo es la práctica de la colecta $(2 \mathrm{Co} 8,9)$ que muestra el valor teológico y eclesiológico: es un acontecimiento de gracia; actualiza la kénosis en vista a la koinonía; hace concreta la igualdad que posibilita la comunión; y manifiesta la unidad y la catolicidad de la Iglesia de Cristo. Esta práctica ha de superar los límites de la comunidad eclesial.

En el capítulo sexto Coda recapitula, "El ága$p e$, 'forma' de la identidad y de la misión de la Iglesia. Una reflexión teológica sintética”. Desde la página 136 hasta la página 167 se ofrece un resumen de lo estudiado y unas indicaciones en perspectiva eclesiológica. Se va a responder a dos relaciones: la primera entre el ágape y la Iglesia (su vida interior, la comunión) y la segunda relación entre el ágape y el anuncio de Cristo que la Iglesia ha de ofrecer hoy al mundo (su misión en el mundo). Con la expresión "forma" el autor indica que el amor divino ofrece a la Iglesia su ser y su actuar, el ágape hace a la Iglesia ser sujeto y obrar como sujeto.

El ágape, 'forma' de la identidad de la Iglesia se elabora en cuatro apartados. Primeramente el aspecto teológico y trinitario del ágape; se usa como categoría cristológica sintética para "describir y anunciar la totalidad del acontecimiento Cristo (...). Baste recordar la 1Jn 3, 16. (...). El ágape es Cristo mismo como acontecimiento de la autocomunicación salvífica del Padre a la historia del hombre en la libertad-unidad del Espíritu Santo" (138).

En un segundo momento se citan las características del ágape como 'forma' de la vida eclesial. Estas parten de la consideración del ágape de Dios en su dimensión cristológica, pneumatológica y trinitaria. 1. "El ágape significa y configura respeto, apertura y proximidad ante la alteridad" (139). 2. La reciprocidad "lleva a cumplimiento el ágape como reconocimiento de la alteridad del rostro del prójimo (...). El ágape se manifiesta, por tanto, como un acontecimiento de unidad en la distinción-libertad, de distinción-libertad en la unidad" (141). 3. Su caracterización kenótica. La alteridad como plenitud de la reciprocidad, presupone la capacidad en el Espíritu de perderse para hallarse. "Es esta la ley trinitaria del ágape. Como el Padre es Él mismo en cuanto es relación, don de sí total al Hijo, y tal es el Hijo en relación con el Padre, así también el creyente es llamado al seguimiento de Jesús, a vivir esta ley pascual de muerte y resurrección en Cristo" (141). 4. El ágape es apertura y efusividad al y en el "tercero". A la vez sucede la comunión y unidad que impulsa la misión. 5. El ágape se caracteriza por su historicidad. "El ágape se expresa en la totalidad del ser humano y de sus múltiples y constitutivas dimensiones de existencia" (142).

El tercer punto habla de la relación entre el ágape eclesial y el Ágape que es Dios. La primera relación es "la iconicidad de la vida de la Iglesia como ágape respecto al misterio de Dios". La segunda relación es la excedencia o superioridad e inagotabilidad que el Ágape de Dios conserva respecto al ágape de la Iglesia.

El cuarto apartado trata del imperativo de la configuración agápica de la Iglesia en todas sus expresiones. Una sola consecuencia, la Iglesia en su interior ha de estar impregnada por la "forma caritatis" y esto se ha de reflejar en sus instituciones. El ágape alcanza a la dimensión espiritual y a toda la expresión histórica de la existencia cristiana, incluyendo toda estructura encarnatoria, toda la actividad de la Iglesia. 
El segundo gran bloque de este último capítulo trata el ágape y la misión de la Iglesia en la perspectiva de la nueva evangelización, invitando a formar comunidades eclesiales maduras. Coda desarrolla este contenido en dos partes: El ágape y el significado integral de la acción evangelizadora de la Iglesia (146); y el ágape en la obra de promoción humana de la Iglesia (150).

Cuando aborda "el ágape y el significado integral de la acción evangelizadora de la Iglesia" afronta la necesidad de superar la alternativa entre promoción humana o liberación y la salvación integral; el anuncio cristiano es el "evangelio del ágape"; la evangelización alcanza a la experiencia histórica de la humanidad y a la raíz espiritual del la persona humana. También plantea la superación de la alternativa entre testimonio y anuncio; para superar la dicotomía se necesita que el ser de la Iglesia se haga misión. Unido a lo anterior, y en tercer lugar, se trata de una superación de la alternativa entre la identidad y el diálogo; hay que comprenderlo desde Cristo, quien es la verdad de Dios y del hombre.

Finalmente al estudiar "el ágape en la obra de promoción humana de la Iglesia" se refiere a una "circularidad hermenéutica" entre la evangelización como anuncio del evangelio del ágape (testimoniándolo y encarnándolo) y la narración del ágape en el anuncio y la celebración en los sacramentos. Esto lo desarrolla en seis vertientes:

1. El horizonte de la interdependencia planetaria como horizonte de la "civilización del amor". Se hace necesario conjugar lo particular con la mundialidad;

2. El significado teológico de la "opción preferencial" por los pobres, Coda afirma: "el amor de Dios, (...), no puede no partir de los últimos por la naturaleza misma del amor de Dios: su paternidad, que se manifiesta dentro de la familia humana surcada por el pecado y la división, no puede menos de privilegiar a aquellos que más sufren y están marginados" (155). Esto se refleja en la gratuidad, la sobriedad, el compartir, la comunión de bienes;

3. La denuncia de las estructuras de pecado y promoción de estructuras de comunión, se trata de proponer estilos de vida, modelos de producción y consumo, y estructuras de poder diversas a las actuales;

4. La dimensión política del ágape como "utopía concreta". Coda dice: "el ágape es la fuente inspiradora y la energía vivificante del compromiso político del cristiano (Cf. GS 36,38) (...). Y al mismo tiempo (...) el ágape se muestra como la "utopía concreta" que la política está llamada a encarnar de modo cada vez más pleno" (159-160);

5. El ágape como principio inspirador de una economía de la comunión, la comunión de bienes en la libertad es la "utopía concreta" que la doc- trina social de la Iglesia propone en el campo económico;

6. La reserva escatológica y el pluralismo, hay una "discrepancia entre el acontecimiento de la Iglesia y la llegada definitiva del Reino. (...). Hay que mantener siempre esta "reserva escatológica", comprometiéndose en la fuerza del Espíritu con todas las energías, según cuanto afirma espléndidamente Gaudium et Spes 38” (166).

En la conclusión, que titula "Santos e inmaculados en el ágape", cita a San Ignacio de Antioquia (Ad Rom 7,2) cuando afirma, en palabras de Coda, que el "éros como cifra sintética de la existencia humana que es crucificado con Cristo y es así purificado, plasmado y transcendido en el ágape como gracia y libertad del Espíritu Santo que nos impulsa, hechos uno en Cristo, hacia el seno del Padre. (...). Este es el Ágape trinitario: Jesucristo Crucificado y Resucitado es el "camino" que viene de Él y a Él conduce y su verdad plena; el Padre, su origen y su morada definitiva; el Espíritu, su luz, su fuerza, su libertad. Y nosotros, por gracia, introducidos en él como Iglesia, somos llamados a invitar a él a todos los hombres y todas las realidades creadas. Con alegría y gratitud. Y mirando a María. Porque María es el icono perfecto del ágape uni-trino vivido en plenitud en la creación y en la historia de la salvación, y como tal ya asunta a madurez definitiva en la gloria. (...). María es icono de la Esposa escatológica del Cordero (cf. Ap 19, 7-8; 21, 1-3; 22, 17), a la que Cristo amó dándose a sí mismo por ella, a fin de "presentársela a sí mismo, sin que tenga mancha ni arruga ni cosa parecida, sino que sea santa e inmaculada" (Ef 5, 27). Es el cumplimiento del designio de salvación del Padre que "en Cristo nos ha elegido antes de la creación del mundo, para ser santos e inmaculados en su presencia, en el ágape” (Ef 1, 4)" (168-169).

Al final ofrece unas acertadas y actualizadas "sugerencias bibliográficas" (170).

Agustina Serrano

DÍEZ MACHO, Alejandro-PIÑERO SÁENZ, Antonio, (Drs.), Apócrifos del Antiguo Testamento, vol. III, Cristiandad, Madrid 1982-2 2002. 613 pp.

Este es el tercer volumen de un total de siete. Se trata de una verdadera nueva edición de la obra dirigida en los años ochenta por Díez Macho. Ahora, bajo la dirección de Antonio Piñero, Ediciones Cristiandad presenta una obra actualizada en su bibliografía, en la traducción de los textos y en algunas notas.

Este tercer volumen presenta los siguientes escritos apócrifos: Salmos de Salomón, Odas de 
Salomón, Oración de Manasés, Libro Cuarto de los Macabeos, Libro Arameo de Ajicar, José y Asenet y Oráculos Sibilinos. El plan de la obra resulta extremadamente interesante tanto para el lector principiante y curioso como para los investigadores que por diversos motivos no requieran consultar el texto original. La traducción castellana de cada libro apócrifo está precedida por una breve e informada introducción que aborda las cuestiones básicas para una mejor comprensión del texto.

En un primer momento, se atiende a aspectos generales de cada obra: presentación del contenido del libro y del plan de la obra y se entrega una descripción general de esta. Posteriormente se enfrentan temáticas de índole histórico-crítica e histórico-tradicional: género literario, autor(es) y lugar de composición. Cuando es posible, se alude al proceso genético de composición. Si parece útil para la comprensión del texto, se lo sitúa en el contexto histórico social correspondiente. Sin lugar a duda esta manera de presentar el texto es tributaria de una particular perspectiva diacrónica con que se analizan los textos. Esta óptica (histórico-crítica e histórico-tradicional) corresponde a la visión en boga en los años de la primera edición del volumen. En una segunda edición para la primera década del nuevo siglo este punto de vista resulta aún valioso, pero debe ser enriquecido con los aportes de nuevas perspectivas lingüísticas y de las ciencias de la comunicación.

En un segundo momento se analizan temáticas relativas a la tradición y transmisión textual. En estos apartados de la obra adquieren relevancia asuntos como la lengua original del escrito, la situación de los manuscritos que dan testimonio del texto y la variedad de versiones antiguas que se conocen. Los autores dedican generosas páginas para estos problemas y entregan datos valiosos que cualquier investigador necesita para dar oficio a su trabajo. Sin lugar a dudas, este es una de las fortalezas de esta colección de textos, por cuanto aporta datos de no simple recolección y que por lo general encontramos en comentarios específicos de cada libro; literatura que no abunda en nuestro castellano. La presencia de estos capítulos aporta versatilidad a la edición, por cuando apunta a satisfacer al lector apenas iniciado y a quien se interesa por un estudio científico del texto.

En las últimas partes de las introducciones se presenta una breve y valiosa bibliografía que incluye las ediciones más relevantes y confiables de los textos originales. También informa sobre títulos de traducciones a lenguas "modernas", artículos de corte general en enciclopedias, introducciones específicas a los apócrifos y otros trabajos de tipo monográfico. Es notable que para esta segunda edición, veinte años más tarde, se complementara la bibliografía con numerosas obras que dan cuenta del avance de la investigación. Se cumple así otra característica deseable de una obra, que procura mostrarse abierta a profundizaciones, que sirva de apertura a un nuevo nivel de comprensión del texto que se edita.

No queda más que celebrar la aparición de esta nueva edición y esperar que la lectura de los libros apócrifos sea un aporte a la investigación del mundo bíblico y también al estudio de la literatura universal, puesto que en muchos casos se trata de obras de alto valor literario que por primera vez se presentan en una traducción castellana.

Mike van Treek

LUQUE, ELISA, La evangelización en América y sus retos. Respuesta de los protagonistas, Ediciones Promesa, San José de Costa Rica, 2002, 108 pp. $21 \times 13,5 \mathrm{~cm}$.

Este libro contiene dos ponencias y dos colaboraciones en obras colectivas. Todas versan sobre el tema del título de la obra. No constituyen un análisis detallado de los problemas planteados, sino que entregan una versión clara y precisa de algunos aspectos. Tienen el valor de exponer una visión ordenada, pero son tan vastos y tan densos los problemas tratados que el lector queda un tanto frustrado.

Si es un especialista, considerará la lectura de estas páginas como una superficial obra de divulgación, y si es un profano, esta visión no le permitirá comprender la terrible complejidad del proceso evangelizador del continente americano. Después de lo publicado, especialmente a raíz del quinto centenario de la llegada de la fe cristiana, el público se ha vuelto un poco más exigente y espera que las publicaciones aporten algo nuevo.

Tras la lectura, quien se prometía conocer mejor a los protagonistas del proceso evangelizador, tanto a quienes vinieron desde España a proclamar la Buena Nueva como a quienes respondieron a la invitación que se les hizo de incorporarse a una nueva sociedad, les queda un vacío respecto a estos últimos.

La autora tiene el mérito de sintetizar bien. En la primera ponencia explica la rápida implantación de la Iglesia por la conjugación de tres factores: el capitalismo mercantilista pujante, la afirmación de las monarquías nacionales y la gran vitalidad eclesial a raíz de la Reforma católica; a lo cual añade el sentido religioso que animaba a las tribus americanas.

Los factores considerados son fácilmente captados por una visión europea, pero le falta analizar los factores propios del mundo indígena. La enemistad y lucha de las tribus en lucha por la hegemonía en la meseta de Anahuac ni siquiera es citada, entre otros muchos factores. 
La segunda ponencia es parte de un estudio sobre las crónicas escritas por religiosos. De las crónicas del franciscano Diego de Landa y del dominico Antonio de Remesal presenta unas pinceladas que enmarca en 16 páginas. Poco para comprender la postura que adoptaron los hombres de la cultura maya ante la novedad traída por los misioneros. El conocimiento del idioma oral es suficiente para penetrar en la cultura de un pueblo, hay otros elementos que deben considerarse.

El tercer capítulo trata de exponer algo del contenido del catecismo zapoteco de Pedro de Feria. Insiste la autora en la preocupación misionera para descubrir al otro, muy propia de la tendencia del humanismo cristiano, presente desde los inicios del proceso evangelizador en América. Constituye un buen ejemplo de análisis de un texto y es lo mejor que trae el libro.

El cuarto tema tratado es la legitimidad de la guerra contra los chichimecas que se planteó en el tercer Concilio de México en 1585. La autora no considera en su exposición los aportes de estudios sobre las características de las guerras fronterizas para realizar un análisis crítico de las posiciones defendidas por juristas y teólogos, que por supuesto ignoraban la dinámica de este tipo de guerra.

La autora es doctora en Historia de América, de una América una y múltiple. Desde lejos solamente suele captarse una imagen que da impresión de unidad. Al marginar la multiplicidad se corre el riesgo de distorsionar la realidad que se desea conocer. Los centros que concentraban una población de cultura en desarrollo evidente, como lo fueron México y Perú, presentaron problemas muy diferentes a las zonas periféricas, donde tribus atrasadas se aislaban en medio de selvas o mantenían un nomadismo periódico permanente. Todo lo cual exige cautela antes de cualquier afirmación. Los mismos misioneros que actuaron en diversos lugares llamaron a cuidarse de generalizar fácilmente cuando de indios se trataba.

\section{Marciano Barrios V.}

BÉDE, HENRI, fsc. Iniciación a la Historia del Instituto de los Hermanos de las Escuelas Cristianas. El siglo XVIII. 1726-1804, Roma, 2002, 260 pp., $23.5 \times 18.5 \mathrm{~cm}$.

Este estudio es, como reza el título, una excelente iniciación a la historia de una institución que fue protagónica en ciertos cambios que se operaron en la educación popular durante el Siglo de las Luces. Entrega informes y documentos indispensables para conocer las vicisitudes sufridas por una congregación durante los decenios revolucionarios de fines de este siglo. Muestra en for- ma objetiva lo peligroso de las afirmaciones categóricas cuando se trata de grupos de personas que actúan en momentos de cambios imperceptibles. Aunque se realicen análisis cuantitativos de cuadros estadísticos, las posiciones se balancean entre la conservación de una tradición y la aceptación inconsciente de los cambios. Al recorrer algunas páginas se vislumbra la afirmación de recias personalidades y el peso sociológico de la presión de grupos y acontecimientos que entregan nuevas perspectivas.

La obra consta de una breve introducción de los cambios socioculturales y económicos de Francia durante el siglo XVIII. Se trata de facilitar la comprensión de la actuación de un grupo de personas, en este caso de los Hermanos de las Escuelas Cristianas de la Salle, durante este siglo, en diversas ciudades de Francia. Al final analiza las fuentes utilizadas y señala que se encuentran en los Archivos de la Casa Generalicia de Roma y en diferentes fondos de archivos.

El primer capítulo expone el desarrollo de la institución durante los años 1726 a 1751. El gobierno del Hermano Timoteo lo expone centrándose en dos personalidades que representan bien la época: los hermanos Jean Jacquot e Irene. Ambos tuvieron que enfrentar no pocas dificultades para afirmarse como entidad en un período en que los sectores sociales bajos y medios, a los que pertenecieron los primeros hermanos, quedaban sometidos a los señores feudales, a los párrocos galicanos y a los intereses de maestros particulares. El autor toma en cuenta los condicionantes del desarrollo y expansión de la Congregación.

El segundo capítulo analiza la estabilización del Instituto en medio de una sociedad que empezaba a cambiar aceleradamente. Es valioso el análisis del autor en torno a las deserciones vocacionales. Señala las dificultades que ofrecía la vocación de hermano, dedicado exclusivamente a la actividad educacional. Era difícil saber si los aspirantes a la admisión eran jóvenes que buscaban un perfeccionamiento espiritual, propio de la vida religiosa o solamente abrazaban una actividad con espíritu propio de un creyente normal. Asimismo, los cortos años dedicados a la formación por las urgencias de las numerosas fundaciones impedían un seguimiento de los nuevos religiosos. Los directores tenían que atender múltiples tareas que no les dejaban tiempo para perfeccionar y terminar la iniciación del noviciado.

Pero las dificultades principales provenían del medio social. Así parece deducirse de dos párrafos interesantes: "Conocidos también por su fidelidad al Papa, los Hermanos sufrieron el acoso de los adversarios de los jesuitas. Se vieron asimilados a ellos e incluso acusados a veces de pretender reemplazarlos...

Distintos miembros de la nobleza o altos magistrados, sobre todo de los parlamentos, trataban sobre todo de defender sus privilegios. Los filósofos, par- 
ticipando del talante de la burguesía a la que en general pertenecían, eran partidarios de cambios en el orden social en la medida en que tal cosa pudiera favorecerlos. Unos y otros, por el contrario, eran hostiles a lo que pudiera contribuir a la evolución de las capas inferiores de la sociedad.

Por esta razón los filósofos y sus adeptos la habían tomado con los Hermanos. Así, un miembro del parlamento de Bretaña, La Cholotais, les reprochará que preparaba a la gente pobre para mejores condiciones de vida. So pretexto de defender el interés público, atacaba el principio de la enseñanza gratuita y universal. Los Hermanos de la Doctrina cristiana, escribía, han llegado para acabar de echarlo todo a perder, enseñar a leer y a escribir a gentes que no habrían debido aprender sino a dibujar y a manejar el cepillo y la lima y no quieren hacerlo.

La Chalotais consiguió la aprobación del mismo Voltaire. Este le escribía: "Le agradezco el que proscriba el estudio entre los campesinos. Yo que cultivo la tierra, aprovecho para solicitarle trabajadores y no administrativos con tonsura. Envíeme sobre todo Hermanos ignorantes para conducir mis arados y uncirlos a ellos...".

Con esta cita me ahorro de mayores comentarios respecto al estudio que muestra la unión de intereses que se sentían amenazados por la enseñanza de los Hermanos a los sectores pobres. Todos ellos consideraban en esos años que una buena organización social imponía que gran número de sus miembros fueran ignorantes. Los Hermanos estaban más cerca del pueblo cristiano que de los miembros del clero y de las órdenes religiosas. Se mantuvieron fieles a sus compromisos religiosos, muy propios de la renovación religiosa del siglo XVII. Pero al mejorar el nivel de instrucción de los artesanos y de los pobres, los Hermanos contribuyeron a despertar en estos sectores las ideas revolucionarias que empezaban a germinar.

En el tercer capítulo, denominado la Consolidación, se exponen los problemas relacionados con la gratuidad de la enseñanza que iniciaban los Hermanos. Sistema que se inspiraba en las ideas de Comenio, las que al igual que las de Rosseau, influían en el sistema implantado en las escuelas de los Hermanos. La gratuidad amenazaba también a los maestros de escuelas menores y especialmente a los maestros calígrafos, los que acusaban a los Hermanos de quitarles su sustento, aceptando niños cuyos padres, a su juicio, habrían podido pagar una escolaridad.

El cuarto y último capítulo aborda la destrucción de la obra consolidada por las medidas tomadas por los gobiernos revolucionarios. El proceso vivido en Francia desde 1789 a 1800 es analizado en razón de las dudas que debían aclarar los Hermanos ante la confusión del momento durante el gobierno de la Asamblea Constituyente y las posturas adoptadas cuando se desató la persecución a los religiosos.
En general, el libro es un excelente aporte a la Historia de la Educación durante el siglo indicado y permite señalar lo que fue más tarde el ideal educacional de Condorcet. El ideario pedagógico de los Hermanos se expone y describe en cada uno de los capítulos. Los principios fundamentales se han conservado en los libros que inspiran la tradición educacional de la Congregación de los Hermanos de las Escuelas Cristianas hasta el presente.

\section{Marciano Barrios V.}

DANIELOU, JEAN, Mensaje evangélico y cultura. Siglo II y III, traducido del francés por Jesús Valiente Malla, Ediciones Cristiandad, Madrid 2002, 521 pp.

El presente estudio no requiere ser presentado ni recenciado, ya que la relevancia que fue adquiriendo desde la publicación del texto original francés, Message évangelique et cultura hellenistique en 1961 es inapreciable. Tantas generaciones jóvenes de estudiosos de la literatura patrística han sacado un provecho innegable de su contenido sugerente, entregado por un gran maestro de Patrología, Jean Danielou. Pero sí vale la pena destacar, que por fin esta obra importante es accesible en una bella traducción española. Con esto se ampliará el círculo de estudiosos que lo podrán usar con tanto provecho como las generaciones anteriores dentro de un contexto sensible y muy interesado en el estudio de los Padres de la Iglesia. Para nuestro contexto latinoamericano, en efecto, esta traducción significará un estímulo importante para continuar profundizando un tema muy candente para nosotros, la evangelización de la cultura.

Anneliese Meis

TONY MIFSUD, Una fe comprometida con la vida -espiritualidad y ética, hoy-, San Pablo, Santiago de Chile, 2002, 92 pp.

El autor es sobradamente conocido por su obra en cuatro volúmenes Moral de Discernimiento, pero desde hace años ha incursionado en el ámbito de la espiritualidad y específicamente de la espiritualidad ignaciana. En este libro se esfuerza por mostrar el vínculo indisoluble que existe entre la auténtica experiencia espiritual y su verificación en la actuación ética, evitando el riesgo de una reducción de la fe a la moral, lo que constituye el moralismo, pero a la vez, la separación entre fe y vida, lo que lleva a una vivencia alienada de la fe. 
En un breve capítulo inicial hace un esfuerzo por precisar los dos conceptos claves del libro: espiritualidad y ética. En un segundo capítulo, traza la historia del origen y desarrollo de la teología moral y de la teología espiritual desde su desgajamiento del tronco común de la teología hasta su constitución en disciplinas autónomas refiriéndose a las conocidas etapas de la historia de la moral católica hasta su renovación en el postconcilio y a las menos conocidas etapas de la historia de la moral católica hasta su renovación en el postconcilio y a las menos conocidas etapas de la evolución de la espiritualidad como experiencia y como disciplina teológica. El tercer capítulo, Verificación ética de la experiencia cristiana, desarrolla la tesis fundamental del libro, es decir, la peculiaridad de la experiencia de fe y su no reductibilidad a la moral, pero a la vez la necesidad de que ella se verifique en una experiencia ética que sea coherente con saberse gratuitamente amados y acogidos por Dios en Jesucristo. Lo anterior se traduce en una ética mo- tivada por la espiritualidad y con una impostación trinitaria, de seguimiento de Jesucristo y de gratuidad, lo que le da un talante fundamentalmente positivo. El último capítulo quiere relacionar todo lo anterior con la espiritualidad ignaciana y su énfasis en el discernimiento donde se encuentran espiritualidad y moral; para ello, da las notas fundamentales de dicha espiritualidad y señala los pasos necesarios para realizar un discernimiento.

Este pequeño libro de divulgación es un intento por dialogar, desde una comprensión renovada de la moral católica, con la inquietud planteada por el Papa Juan Pablo II en la Encíclica Veritatis Splendor $\mathrm{N}^{\circ} 88$ cuando afirma que "una de las preocupaciones pastorales más agudas de la Iglesia en el presente momento de secularismo" es la separación entre fe y moral que se da no solo entre los creyentes, como es obvio, sino también entre los creyentes cuyos "criterios de juicio y de elección... se presentan frecuentemente... como extraños e incluso contrapuestos a los del "Evangelio".

José Arteaga Ll. 